\title{
DINÂMICA DEMOGRÁFICA DA POPULAÇÃO RURAL: O CASO DO COREDE ALTO JACUÍ, RIO GRANDE DO SUL
}

\author{
SPANEVELLO, Rosani Marisa ${ }^{1}$ \\ MOREIRA, Sandro da Luz ${ }^{2}$ \\ BOSCARDIN, Mariele ${ }^{3}$
}

RESUMO: Ao longo das últimas décadas, o comportamento demográfico da população rural brasileira e gaúcha tem sido variável em números, apresentando um decréscimo devido à migração juvenil e queda da taxa de fecundidade das mulheres, além do envelhecimento somado ao aumento da expectativa de vida. Este artigo tem como objetivo analisar este comportamento a partir dos dados censitários do Instituto Brasileiro de Geografia e Estatística - IBGE. Os dados selecionados dizem respeito aos três últimos Censos Demográficos - 1991, 2000 e 2010. A região analisada são os 14 municípios do Conselho Regional de Desenvolvimento (COREDE) Alto Jacuí Rio Grande do Sul. As análises dos dados apontam que a dinâmica populacional deste COREDE é marcada pelo processo de migração juvenil, bem como o aumento do envelhecimento da população rural e da expectativa de vida e da diminuição das taxas de fecundidade. Este comportamento sugere que os municípios do COREDE em questão podem ter dificuldades na reprodução social e econômica das propriedades devido à saída dos jovens da ocupação agrícola e do meio rural. Da mesma forma, a diminuição da taxa de fecundidade implica em dificuldades na reposição da população rural. Além disso, o envelhecimento das pessoas que ficam no campo sugere um cenário composto por pessoas de mais idade em detrimento da ausência de jovens. Diante deste cenário, torna-se necessário pensar ações e estratégias para amenizar estes impactos sociais no meio rural analisado.

Palavras-chave: Meio rural. População. Reprodução social.

SUMMARY: Over the last decades, the demographic behavior of the rural population from Rio Grande do Sul and Brazil has been variable in numbers, showing a decrease due to the youthful migration and the fall in the female fertility rate, besides the aging and the increasing of life expectancy. The article aims to analyze this behavior from the census data of the Brazilian Institute of Geography and Statistics - IBGE. The selected data refer to the last three Demographic Censuses - 1991, 2000 and 2010. Fourteen cities belonging to the Regional Development Council (COREDE) Alto Jacuí - Rio Grande do Sul were analyzed. The analysis of the data indicates that the population dynamics of this COREDE is defined by the process of youth migration, as well as the increasing of aging and life expectancy of the rural population and the reduction in fertility rates. This behavior suggests that the cities of the COREDE mentioned may have difficulties in social and economic reproduction of their properties due to the exit of young people from the agricultural occupation and the rural environment. Likewise, the fertility reduction rate brings difficulties in population replacement. In addition, the aging of those who stays in the rural area is made up of older people because of the absence of young people. According to this scenario, it is necessary to think about actions and strategies to reduce these social impacts in the rural environment analyzed.

Keywords: Rural environment. Population. Social reproduction.

\section{INTRODUÇÃO}

As questões demográficas, especialmente no que tange seus impactos e desafios para o crescimento econômico dos países, impulsionam importantes debates ao longo do tempo. No caso brasileiro, as mudanças e transformações demográficas tornaram-se mais visíveis predominantemente a

\footnotetext{
${ }^{1}$ Professora Associada do Departamento de Zootecnia e Ciências Biológicas e do Programa de Pós Graduação em Agronegócios da Universidade Federal de Santa Maria, Campus Palmeira das Missões - RS

${ }^{2}$ Mestrando do Programa de Pós Graduação em Agronegócios da Universidade Federal de Santa Maria, Campus Palmeira das Missões

${ }^{3}$ Mestre em Desenvolvimento Rural pela Universidade Federal do Rio Grande do Sul
} 
partir da década de 1950. Dentre as principais transformações observadas, podem-se destacar as quedas nos níveis de fecundidade entre as mulheres, o aumento na expectativa de vida e a migração rural urbana, especialmente da população jovem.

Estas alterações demográficas além de afetarem o crescimento populacional, ocasionam mudanças na estrutura etária da população, reduzindo a proporção das crianças e aumentando, em um primeiro momento, a proporção dos adultos, e em um período posterior, a proporção dos idosos, dando origem a um novo paradigma demográfico, caracterizada pela redução da população em idade ativa e da força de trabalho.

De acordo com Ávila e Machado (2015), inicialmente com as quedas nos níveis de fecundidade entre as mulheres e o aumento na expectativa, uma grande parcela da população está abaixo da idade de trabalho, com o tempo, esse contingente migra para a faixa seguinte de idade, compondo a população em idade ativa (PIA) e, finalmente, vem a fase do envelhecimento na qual o ímpeto econômico diminui.

A população em idade ativa é composta por adultos de 15 a 64 anos sendo considerada potencialmente produtiva. Assim, a taxa de dependência é obtida pela soma das crianças ( 0 a 14 anos) e idosos (acima de 65 anos), dividida pela população adulta. De maneira arbitrária, são considerados como dependentes as crianças e os idosos (WONG; CARVALHO, 2006). Conforme projeções realizadas por Alves e Cavenaghi (2012), a partir do final da década de 2030 o número de habitantes de 65 anos ou mais será maior do que o de habitantes de 0 a 14 anos.

Wong e Carvalho (2006) corroboram indicando que por volta de 2050 o tamanho e a participação da população de 65 anos ou mais atingirão uma proporção mais elevada daquela vivida, atualmente, em qualquer país europeu. Desta forma, estima- se que por volta de 2050, o Brasil irá defrontar-se com a difícil situação de atender uma sociedade bastante envelhecida.

Além disso, o Brasil deixou de ser uma sociedade predominantemente rural para se tornar uma sociedade predominantemente urbana, sobretudo a partir dos anos 60. De acordo com dados do Instituto Brasileiro de Geografia e Estatística (IBGE), o decréscimo da população rural brasileira é visível a cada contagem de Censo Populacional.

Conforme o Censo de 1991, a população que residia no meio rural era de aproximadamente 36 milhões de pessoas, diminuindo para aproximadamente 30 milhões em 2010. No caso do estado do Rio Grande do Sul, o cenário não é distinto. De acordo com dados do Censo Populacional de 1991, a população rural perfazia um total de aproximadamente 2,1 milhões de pessoas, reduzindo para aproximadamente 1,5 milhões em 2010, havendo um decréscimo em torno de $25 \%$.

Dentre os fatores que contribuem para esta realidade de esvaziamento demográfico de meio rural brasileiro, Maia (2014) destaca fatores endógenos à estrutura familiar, tais como queda nas taxas de fecundidade e fragmentação das famílias, bem como redução no tamanho médio das mesmas. Além destes, o autor cita os fatores exógenos, sobretudo a adoção de tecnologias na agricultura, que propiciaram liberação de mão-de-obra e mesmo com o avanço e modernização deste setor, as cidades tradicionalmente oferecem ocupações com maior remuneração associada à renda mensal (o que não ocorre via de regra na agricultura) e com maior valorização social.

Considerando que ao longo das décadas, a dinâmica populacional rural brasileira e gaúcha tem mostrado um quadro comportamental variável quanto ao seu tamanho (em termos numéricos) e quanto à disposição espacial (migração rural-urbana) somado à redução das famílias e diminuição da queda da taxa de fecundidade entre as mulheres rurais, este artigo tem como objetivo analisar este comportamento a partir dos dados censitários expostos pelo Instituto Brasileiro de Geografia e Estatística - IBGE. Os dados selecionados dizem respeito aos três últimos Censos Demográficos - 1991, 2000 e 2010 tendo como espaço geográfico da análise os 14 municípios do Conselho Regional de Desenvolvimento 
Desenvolvimento (COREDE) Alto Jacuí ${ }^{4}$ pertencente ao Rio Grande do Sul.

A escolha deste espaço geográfico de pesquisa deve-se a estudos e pesquisa dos autores neste COREDE voltados a compreender a temática juvenil rural e as possibilidades sucessórias das propriedades rurais. Para empreender a análise proposta leva-se em conta a diversidade do processo migratório, conforme exposto por Maia e Buainain (2015) em que os autores afirmam ser necessário considerar que a saída das pessoas do campo não ocorre igualmente entre as regiões, os próprios motivos para migrar tendem a ser distintos gerando cenários migratórios distintos entre as regiões, entre os migrantes, entre os seus níveis de qualificação, sexo e idade.

A estrutura do artigo contempla as seguintes seções: a primeira aborda a discussão do êxodo seletivo, taxa de fecundidade e mudanças na estrutura etária; o segundo traz um detalhamento da área geográfica selecionada para análise; a terceira trata da apresentação dos resultados através da discussão da evolução das questões demográficas no COREDE Alto Jacuí e, por fim, as principais considerações e apontamentos do trabalho.

\title{
1 ÊXODO RURAL SELETIVO, FECUNDIDADE ABAIXO DOS NÍVEIS DE REPOSIÇÃO E AS MUDANÇAS NA ESTRUTURA ETÁRIA
}

Segundo Alves e Cavenaghi (2012) no período de 1970 a 1980 no Brasil 12,4 milhões de pessoas migraram representando $30 \%$ da população rural no período, nos anos entre 1980 a 1991, 10,3 milhões de pessoas saíram do meio rural representando 26,42\%, no período de 1991 a 2000 9,07 milhões de pessoas migraram representando $25,17 \%$ e no período de 2000 a 2010 migraram 5,6 milhões de pessoas representando $17,61 \%$ da população rural no período.

O deslocamento da população rural para o meio urbano tende a gerar contornos distintos entre as regiões, os níveis de qualificação, a idade entre outras questões. Neste sentido, Neves e Schneider (2015) corroboram afirmando que as mudanças não são homogêneas e acentuam-se especialmente e com maior intensidade em algumas regiões do país, como o caso da região Sul. Maia e Buainain (2015) argumentam sobre as particularidades migratórias da população rural do Sul do país através partir da seguinte ótica:

\begin{abstract}
A dinâmica da população rural no Sul merece algumas considerações adicionais, não somente por ser uma região de consolidação da agricultura familiar, mas também pela sua relevância em termos de produção agrícola do país. Essa região apresentou a queda mais acentuada da população residente em domicílios rurais entre 1991 e 2010: $28 \%$. Dois aspectos principais contribuíram para essa dinâmica. Primeiro, a região apresentou a menor taxa de crescimento populacional no país (24\% entre 1991 e 2010), refletindo um estágio mais avançado de transição demográfica. Segundo, as expressivas diferenças entre os ritmos de crescimento populacional urbano ( $42 \%$ positivo) e rural (28\% negativo) indicam um fluxo ainda persistente e intenso de migração rural-urbano na região. A região Sul apresenta, tradicionalmente, uma agricultura familiar dinâmica e bons indicadores de desenvolvimento humano. A persistência da migração rural-urbano, neste caso, sugere que a migração não pode ser associada unicamente à fuga da pobreza rural, mas também, por exemplo, à atração da população rural pela dinâmica socioeconômica urbana. Também é nesta região que se registram os melhores indicadores sociais da população rural, incluindo o acesso à educação, o que reforçaria a hipótese de que a mudança na equação decisória da migração, com o deslocamento dos tradicionais fatores de expulsão para os fatores de atração.
\end{abstract}

\footnotetext{
${ }^{4}$ Os Conselhos Regionais de Desenvolvimento - COREDEs foram criados oficialmente pela Lei 10.283 de 17 de outubro de 1994, e referem-se a um fórum de discussão para a promoção de políticas e ações que visam o desenvolvimento regional. O estado do Rio Grande do Sul conta, atualmente, com 28 Conselhos Regionais de Desenvolvimento (DE MERA, NETTO, 2014a, 2014b).
} 
Para Neves e Schneider (2015) atualmente a migração no Sul tem sido mais direcionada a grupos sociais específicos, como os jovens que vivem no meio rural, os quais são mais propensos a migrarem para os centros urbanos à procura do primeiro emprego e de melhores oportunidades de renda.

A respeito disso, cabe destacar que, embora, o êxodo rural permanece presente até os dias atuais, o mesmo transforma-se, nas últimas décadas, de um êxodo rural "generalizado" para um processo mais "seletivo" (CAMARANO; ABRAMOVAY, 1998; ANJOS; CALDAS, 2005; FROELICH et al., 2011). Ou seja, a migração remete às cidades a população mais jovem, ou seja, em idade ativa e altamente produtiva, deixando para traz uma população envelhecida acelerando o fenômeno de envelhecimento da população rural (CAMARANO; ABRAMOVAY, 1998; ANJOS; CALDAS, 2005).

De acordo com dados do IBGE, em 1991 residiam no meio rural brasileiro aproximadamente 7 milhões de jovens (15 a 24 anos) ${ }^{5}$, reduzindo para aproximadamente 5 milhões em 2010, refletindo em uma redução de quase $27 \%$. No estado, de um total de aproximadamente 3,8 milhões de jovens em 1991, o número baixou para 2,3 milhões em 2010, representando uma redução de mais ou menos 39\%.

Por outro lado, simultaneamente a diminuição da população jovem houve um acréscimo no percentual da população idosa (acima de 60 anos $)^{6}$ residente no meio rural. Conceitualmente abordando o termo envelhecimento populacional, Carvalho e Garcia (2003) destacam que o mesmo refere-se a maior proporção de idosos em relação ao conjunto total da população. $\mathrm{O}$ índice de envelhecimento é representado pela população de 65 anos ou mais sobre a população de 0 a 14 anos.

No caso brasileiro, de acordo com dados do IBGE, em 1991 a população idosa perfazia um total de aproximadamente 2,5 milhões de pessoas, aumentando para aproximadamente 3,3 milhões em 2010. Em relação à população idosa estadual, o acréscimo foi de aproximadamente $20 \%$, tendo em vista que de aproximadamente 217 mil pessoas, houve um aumento para 270 mil.

A esse respeito, Maia (2014) indica que houve acréscimo nos índices de envelhecimento da população rural brasileira, que passaram de 9,7\% em 1991 para 21,4\% em 2010. Ou seja, o número médio de idosos para cada grupo de 100 jovens mais que dobrou, passando de 9,7 para 21,4. De acordo com dados do Banco Mundial (2011), tendência é que esses índices aumentem, ou seja, em 2050 essa proporção poderá ser de 100 crianças para 172,7 idosos. Evidencia-se, portanto, o claro processo de envelhecimento da população brasileira, o qual deverá permanecer e acentuar-se ainda mais nas próximas décadas.

Somada à migração dos jovens, a evolução das variáveis demográficas, especialmente as quedas nas taxas de fecundidade entre as mulheres e o aumento na expectativa de vida, acentuam ainda mais a tendência ao envelhecimento populacional rural em períodos mais recentes. Em suma, taxas de natalidade e mortalidade menores transformam a estrutura etária da população.

De acordo com o IBGE, a evolução nos níveis de mortalidade pode ser avaliada por meio da esperança de vida ao nascer, que constitui um indicador síntese dessa variável, sendo expresso pelo número de anos esperados que se viva um recém-nascido estando este exposto às taxas de mortalidade observadas em uma determinada população em dado período. Em relação às taxas de fecundidade, as mesmas referem-se a uma estimativa do número de filhos que uma mulher apresenta ao longo da vida durante sua fase fértil ou período reprodutivo, sendo calculada pela razão entre o número de nascimentos e o número de mulheres em idade fértil, e representada pelo período reprodutivo entre 15 a 49 anos.

Analisando as taxas de fecundidade, nas últimas décadas, evidenciou-se grande redução nos níveis desta variável, o que tem gerado uma transição nos níveis de fecundidade. As taxas de fecundidade entre as brasileiras, representado por 6,2 filhos por mulher em 1940, reduziram-se para 1,9 filhos por

${ }^{5} \mathrm{O}$ IBGE que considera jovens as pessoas com idade entre 15 e 24 anos.

${ }^{6}$ Segundo o IBGE, são idosos pessoas com 60 anos ou mais.

Nucleus,v.16,n.1,abr.2019 
mulher em 2010, devendo chegar a 1,7 filhos por mulher em 2020.

Para Zuanazzi (2015), a fecundidade é o que impacta de forma mais significativa na estrutura etária populacional. No caso brasileiro, a acentuada queda nos níveis deste indicador ao longo das décadas foi o principal fator desencadeador da redução nas taxas de crescimento populacional, o qual passou de 3,04\% em 1960 para 1,05\% em 2008, e, de acordo com projeções, poderá chegar a valor negativo em 2050 , representado por $-0,291 \%$.

Analisando as taxas de fecundidade por situação de domicílio, Godoi (2014), com base nos dados do IBGE, evidencia que nas últimas décadas as diferenças entre mulheres residentes no meio urbano e no meio rural reduziram-se. Em 1970 a diferença era de 3,1 filhos, passando para 1,31 em 2000 e 0,84 filhos em 2010. Ou seja, no ano de 2000 as taxas de fecundidade entre as mulheres residentes no meio urbano eram representadas por 2,18 e no meio rural, 3,49 filhos por mulher. Em 2010, houve uma redução, passando a representar 1,79 no meio urbano e 2,63 filhos por mulher no meio rural.

Em relação às regiões brasileiras, Zuanazzi (2015) indica que a Região Sul e a Sudeste, antecipadamente às demais regiões, alcançaram taxas de fecundidade abaixo das taxas de reposição nos anos 2000, com uma tendência de redução acelerada, enquanto o país, como um todo, baixou desse patamar em meados daquela década. A taxa de reposição populacional, como o próprio nome indica, corresponde a reposição da população e está intimamente relacionada com a taxa de fecundidade. Segundo o IBGE, a média de fecundidade deve ser de 2,1, uma vez que um casal é formado por duas pessoas, o que equilibra o número de habitantes. Em outras palavras, para assegurar a reposição populacional, o número de filhos por mulher deve ser superior a 2,1.

Contudo, a tendência de diminuição da fecundidade permaneceu em todas as Unidades Federativas, conforme apontam os dois últimos Censos e as Pesquisas Nacionais por Amostra de Domicílios (PNADs). De acordo com Zuanazzi (2015), no caso do Rio Grande do Sul, em 2010, o estado apresentava taxa de fecundidade de 1,75, o que o colocava em quinto lugar no ranking de menor valor entre todos os estados brasileiros, atrás apenas de São Paulo, Rio de Janeiro, Santa Catarina e Distrito Federal.

Tratando-se das taxas de fecundidade no Rio Grande do Sul por situação de domicílio, Zuanazzi (2015), observa que, em 2010, as moradoras de áreas rurais e as de áreas urbanas apresentavam, respectivamente, taxas de fecundidade igual ou abaixo do nível de reposição, sendo representado por 2,01 para as gaúchas residentes no meio rural, frente a 1,70 das residentes em áreas urbanas.

Com isso, observa-se que, apesar das taxas de fecundidade entre as mulheres residentes no meio rural permanecerem maiores comparativamente as mulheres residentes no meio urbano, a redução ocorreu de forma bastante significativa, sobretudo, entre os anos de 2000 e 2010. Maia (2014) salienta a queda do número de membros por domicílio nas áreas rurais (de 4,7 em 1991 para 3,6 em 2010), o aumento da participação de casais sem filhos nas mesmas áreas (de $4 \%$ para $12 \%$ no último ano) e a redução nas faixas etárias mais jovens (MAIA 2014).

Por outro lado, paralelamente a redução nas taxas de fecundidade, houve um aumento na expectativa de vida. Conforme dados do IBGE, na década de 1980 a expectativa de vida do brasileiro era igual 62,5 anos, aumentando para 73,7 em 2010. Isso significa dizer que houve um acréscimo de 11,2 anos em apenas 30 anos. As principais causas da redução nos níveis de mortalidade dizem respeito ao avanço no sistema de saúde pública e previdência social, além de avanços na indústria química farmacêutica que auxiliaram na redução e controle de diversas doenças intensificando ainda mais o envelhecimento da população rural.

Em síntese, esta nova dinâmica demográfica (redução da participação dos grupos etários mais jovens e pelo crescimento daqueles mais idosos) pressupõe um repensar sobre o futuro das regiões rurais. 
Este repensar está atrelado aos impactos que estes processos demográficos podem gerar sobre o meio rural. Entre as principais consequências estão os processos de envelhecimento que está diretamente atrelado a migração juvenil; a masculinização que é afetada pelo êxodo seletivo além das mudanças no tamanho e número de famílias e da própria manutenção das propriedades rurais, pois a saída dos jovens pode dificultar a continuidade das mesmas. Estes aspectos são discutidos de forma mais detalhada no item 3 a partir dos resultados apresentados.

\section{CONSELHO REGIONAL DE DESENVOLVIMENTO (COREDE) ALTO JACUÍ}

O Conselho Regional de Desenvolvimento Alto Jacuí (COREDE Alto Jacuí) situado na região Noroeste do estado é um dos 28 Conselhos Regionais de Desenvolvimento do Rio Grande do Sul. De acordo com informações do Governo Federal (2010), o referido COREDE possui uma população total de 162.657 habitantes e uma área de 6.905,5 km². Sendo composto por 14 municípios, Cruz Alta se destaca como município polo regional. Além deste, os municípios de Boa Vista do Cadeado, Boa Vista do Incra, Colorado, Fortaleza dos Valos, Ibirubá, Lagoa dos Três Cantos, Não Me Toque, Quinze de Novembro, Saldanha Marinho, Salto do Jacuí, Santa Bárbara do Sul, Selbach e Tapera também compõe o COREDE. A localização geográfica dos referidos municípios é apresentada na Figura 1:

Figura 1: Localização Geográfica do COREDE Alto Jacuí.

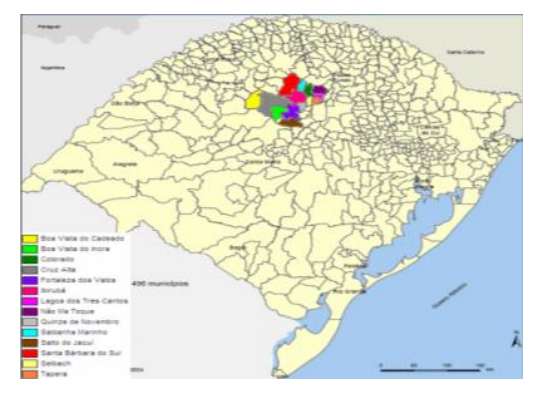

Fonte: Corrêa, et. al., (2010).

O trabalho de Mera e Netto (2014b) aponta que a região do COREDE Alto Jacuí apresenta uma realidade em termos de produção agropecuária baseada em grãos como milho, soja e trigo, além da produção leiteira. Ainda, segundo os autores (2014b, p. 772).

Contrariando a realidade de muitas regiões do Estado - onde há diversidade de ocupações no meio rural, como residência, esporte e lazer, que pode inverter o movimento de uma fração da população em direção às áreas rurais - na região do Alto Jacuí, muito aquém de representar uma função paisagística, cultural ou ambiental, predomina a função produtiva. Assim, na região, há coincidência entre espaço rural e a atividade agrícola, sendo as atividades não agrícolas pouco exploradas no espaço rural da região.

Considerando a evolução populacional do COREDE, segundo dados da Fundação de Economia e Estatística (FEE, 2016), a população total em 2015 era de 159.743 habitantes. Ainda, segundo a FEE (2016), o percentual de crianças (0 a 14 anos) é de 19,03\% (semelhante ao percentual do Rio Grande do Sul), já o percentual de idosos (65 anos ou mais) no COREDE é de 11,73\% sendo ligeiramente superior a média do estado (10,68\%), ou seja, têm-se mais idosos no COREDE estudado, cuja expectativa de vida chega a 73, 2 anos. 
Lisboa e Bagolin (2009), analisando a evolução da distribuição da população gaúcha entre os meios urbano e rural do Rio Grande do Sul, afirmam que o estado passou por uma profunda reestrutura populacional nas últimas décadas, com o esvaziamento das zonas rurais. Ainda, segundo o trabalho das autoras, os municípios com maior população rural estão concentrados na região norte do RS, o qual não inclui nenhum dos municípios do COREDE analisado.

Com relação ao rural do COREDE, conforme a análise de todos os Censos Demográficos realizados no país, em 1970 a população rural dos municípios que o compõem somava 53.505 habitantes, em 1980 chegava a 43.240, já em 1991 o número de habitantes caiu para 38.888, sendo que esta queda seguiu nos últimos dois Censos: eram 31.705 habitantes no Censo Demográfico de 2000 e 25.171 no Censo de 2010. Isso significa dizer que entre 1970 a 2010 a população rural pertencente a este COREDE diminui praticamente pela metade conforme também já mostrou o trabalho de DE MERA e NETTO, 2014a; 2014b. Acompanhamento à tendência da redução da população rural, a população juvenil apresenta-se da seguinte forma: 10.955 habitantes no Censo de 1970, 9.636 na contagem de 1980, 6.706 em 1991, 5.063 em 2000 e 3.658 segundo a contagem no último Censo em 2010. Ou seja, a redução é de aproximadamente 65\% se contarmos do Censo de 1970 até 2010.

As questões migratórias do COREDE Alto Jacuí entre 2005 e 2010, segundo o trabalho realizado pela FEE (2016), mostram que houve uma perda de 5.441 pessoas, representando uma taxa líquida de $3,73 \%$ do total da população. Quanto o perfil destes migrantes trata-se de jovens com faixa etária entre 20 a 34 anos e com alta escolaridade, o que pode significar a perda de pessoas qualificadas e como potencial inovador, além da perda da força de trabalho jovem na agropecuária, comércio e indústria (FEE, 2016).

Para Maia e Buainain (2015) a escolaridade em um papel importante no processo de migração. Segundo os autores, a escolaridade acaba definindo quem assume os empregos mais remunerados nas áreas urbanas e cumpre um papel importante na motivação para migrar, bem como nos resultados da migração dos residentes rurais, especialmente na qualificação do mercado de trabalho em que se colocam.

\section{A EVOLUÇÃO DAS QUESTÕES DEMOGRÁFICAS NO COREDE ALTO JACUÍ}

\subsection{A população Rural Jovem}

De modo geral, conforme a Tabela a seguir, verifica-se que a população de jovens rurais dos municípios que compõem o COREDE apresenta um decréscimo quando comparado os dados dos Censos demográficos de 1991 até 2010.

Neste intervalo de três décadas, a quase totalidade dos municípios analisados perdeu população jovem sendo mais expressivo em Não Me Toque, Ibirubá e Cruz Alta com registro de queda aproximadamente 50\% da população rural juvenil. De Mera e Neto (2014a, 2014b), em seu estudo na região que compõe o COREDE do Alto Jacuí confirma que os jovens deixam o meio rural procurando atividades

menos sofridas e principalmente um salário fixo. Por outro lado, municípios como Salto do Jacuí, Tapera e Selbach registram aumento de jovens rurais.

No conjunto dos municípios, o percentual de jovens comparativamente ao total da população rural fica entre 11 a quase $20 \%$. A partir deste cenário pode-se inferir que tem municípios com percentual de jovens menor que a média do COREDE (que segundo o Censo Demográfico de 2010 é de 14,5\%) e do Rio Grande do Sul (com percentual de 14,6\%). 
Tabela 1: Dinâmica Populacional Rural Jovem no COREDE Alto Jacuí entre o período de 19991 e 2010.

\begin{tabular}{|c|c|c|c|c|}
\hline \multirow[t]{2}{*}{ Municípios $^{7}$} & & \multicolumn{3}{|c|}{ Censos Demográficos } \\
\hline & & 1991 & 2000 & 2010 \\
\hline \multirow[t]{3}{*}{ Boa Vista do Cadeado } & População Rural & 3.028 & 2.202 & 1.969 \\
\hline & População Rural Jovem & - & - & 314 \\
\hline & $\%$ de Jovens Rurais & - & - & 15,94 \\
\hline \multirow[t]{3}{*}{ Boa Vista do Incra } & População Rural & 2.695 & 1.841 & 1.701 \\
\hline & População Rural Jovem & - & - & 258 \\
\hline & $\%$ de Jovens Rurais & - & - & 15,16 \\
\hline \multirow[t]{3}{*}{ Colorado } & População Rural & 3.084 & 2.164 & 1.706 \\
\hline & População Rural Jovem & 522 & 351 & 262 \\
\hline & $\%$ de Jovens Rurais & 16,92 & 16,21 & 15,35 \\
\hline \multirow[t]{3}{*}{ Cruz Alta } & População Rural & 6.303 & 5.887 & 2.227 \\
\hline & População Rural Jovem & 1.098 & 943 & 272 \\
\hline & $\%$ de Jovens Rurais & 17,42 & 16,01 & 12,21 \\
\hline \multirow[t]{3}{*}{ Fortaleza dos Valos } & População Rural & 2.640 & 2.260 & 1.582 \\
\hline & População Rural Jovem & 493 & 360 & 232 \\
\hline & $\%$ de Jovens Rurais & 18,67 & 15,92 & 14,66 \\
\hline \multirow[t]{3}{*}{ Ibirubá } & População Rural & 6.114 & 5.112 & 3.968 \\
\hline & População Rural Jovem & 1.054 & 843 & 530 \\
\hline & $\%$ de Jovens Rurais & 17,23 & 16,49 & 13,35 \\
\hline \multirow[t]{3}{*}{ Lagoa dos Três Cantos } & População Rural & 1.713 & 952 & 791 \\
\hline & População Rural Jovem & - & 170 & 100 \\
\hline & $\%$ de Jovens Rurais & - & 17,85 & 12,64 \\
\hline \multirow[t]{3}{*}{ Não Me Toque } & População Rural & 3.822 & 2.619 & 1.970 \\
\hline & População Rural Jovem & 597 & 418 & 227 \\
\hline & $\%$ de Jovens Rurais & 15,62 & 15,96 & 11,52 \\
\hline \multirow[t]{3}{*}{ Quinze de Novembro } & População Rural & 2.241 & 1.815 & 1.692 \\
\hline & População Rural Jovem & 394 & 271 & 233 \\
\hline & $\%$ de Jovens Rurais & 17,58 & 14,93 & 13,77 \\
\hline \multirow[t]{3}{*}{ Saldanha Marinho } & População Rural & 1.679 & 1.356 & 942 \\
\hline & População Rural Jovem & 278 & 259 & 140 \\
\hline & $\%$ de jovens rurais & 16,55 & 19,10 & 14,86 \\
\hline \multirow[t]{3}{*}{ Salto do Jacuí } & População Rural & 3.397 & 3.043 & 1.672 \\
\hline & População Rural Jovem & 652 & 582 & 343 \\
\hline & $\%$ de Jovens Rurais & 19,19 & 19,12 & 20,51 \\
\hline \multirow[t]{3}{*}{ Santa Bárbara } & População Rural & 3.799 & 2.476 & 1.844 \\
\hline & População Rural Jovem & 686 & 356 & 264 \\
\hline & $\%$ de Jovens Rurais & 18,05 & 14,37 & 14,31 \\
\hline \multirow[t]{3}{*}{ Selbach } & População Rural & 2.525 & 2.073 & 1.479 \\
\hline & População Rural Jovem & 445 & 263 & 216 \\
\hline & $\%$ de Jovens Rurais & 17,62 & 12,68 & 14,60 \\
\hline \multirow[t]{3}{*}{ Tapera } & População Rural & 3.284 & 1.948 & 1.628 \\
\hline & População Rural Jovem & 487 & 247 & 267 \\
\hline & $\%$ de Jovens Rurais & 14,82 & 12,67 & 16,40 \\
\hline
\end{tabular}

Fonte: IBGE (Censo Populacional, 1991-2010). Elaborado pelos autores.

${ }^{7}$ Cabe destacar que, para os municípios em que não se apresenta os dados é devido ao fato de que os mesmos não haviam criados ou emancipados até a data dos Censos em questão, sendo pertencentes a outros municípios, sobretudo ao município de Cruz Alta.

Nucleus,v.16,n.1,abr.2019 
Embora os municípios analisados não apresentem valores distintos a média estadual, sendo maior o número de municípios com valores semelhantes ou acima, é notável apresentou um aumento do número de jovens (Salto do Jacuí), enquanto os demais apresentaram quedas ainda que não expressivas. Isso significa dizer que o processo migratório atinge os municípios não com a mesma intensidade, mas trata-se de um processo recorrente. Ou seja, a leitura destes dados reforça a tese de que a migração, de forma mais ou menos intensa, ocorre no meio rural do COREDE Alto Jacuí.

Diversos estudos apontam os jovens deixam as propriedades e tendem a não voltar para se ocupar da agricultura ou até mesmo podem voltar através de um processo de recampenização ( PLOEG, 2008).

Estudos pioneiros ${ }^{8}$ realizados em países europeus (como é o caso da França) sobre a temática da saída dos jovens do campo e a implicação socioeconômica desta saída para as famílias e para o campo, reforçam que mesmo com a modernização das atividades agropecuárias, ampliação dos meios de comunicação e transporte, maior nível educacional, poucos jovens vem à perspectiva de ficar na condição de agricultor, especialmente pelas dificuldades do trabalho e remuneração quando comparado com o meio urbano. Brumer (2014) argumenta que a saída ou permanência dos jovens está atrelada aos fatores de atração ou de expulsão no campo.

Spanevello et al. (2014) afirma que possibilidade de permanência está atrelada a uma série de estratégias usadas pelos pais para cativar os filhos a permanecer nas propriedades e assumir os negócios, podendo ser de ordem material ou simbólica. Para Gasson e Errington (1993), em trabalho realizado no Reino Unido, a permanência está relacionada com a forma como os pais favorecem a sucessão dos filhos nos negócios podendo ser mais favorável de forma autônoma ou em parceria dividindo a gestão das atividades e a renda com os futuros gestores.

No Brasil, o trabalho de Camarano e Abramovay realizado no final da década de 1990, com base em dados censitários, apontava a migração juvenil com um processo social importante para o meio rural, especialmente pela maior saída das moças podendo acarretar processos com a masculinização. Em análise de contextos mais regionais como é o caso do sul do país Silvestro et al. (2001), a saída dos jovens significa a perda de um potencial inovador no meio rural, devido ao fato desta geração ter maior conhecimento técnico que as gerações anteriores, além da perda do tecido social das comunidades rurais e não necessidade de se manter mais escolas e centros comunitários devido ao esvaziamento demográfico. Ou seja, a migração juvenil representa no médio e longo prazo o comprometimento do processo de sucessão da atividade agrícola familiar, colocando em risco a sustentabilidade da mesma, bem como da própria sociedade rural como um todo, visto que os jovens constituem a força renovadora para o desenvolvimento desta forma social de organização do trabalho e da produção.

Ou seja, a migração dos jovens, atrelado à redução no número de filhos acaba reduzindo os candidatos potenciais a permanecer no meio rural e na atividade agrícola. Diante destes fenômenos as perspectivas sucessórias na agricultura, especialmente a familiar, ficam restritas, com grandes chances dos poucos candidatos que restam à sucessão migrarem para o meio urbano após concluírem o ensino básico.

Diante dessas questões, Neves e Schneider (2015) corroboram afirmando que há crescente preocupação em relação à viabilidade da agricultura familiar e a disponibilidade de força de trabalho no meio rural, tendo em vista que a reprodução deste tipo de agricultura é predominantemente endógena, de modo que a diminuição da população jovem reduz as perspectivas de reprodução dessa atividade econômica.

\footnotetext{
${ }^{8}$ Bourdieu (2000), Champagne (1986)
} 


\subsection{Envelhecimento da população rural no COREDE Alto Jacuí}

Estudos como o de Maia e Buainain (2015) sugerem que a migração seletiva nas áreas rurais intensifica não apenas a masculinização, mas também o envelhecimento da população rural. No Brasil, segundo Maia e Buainain (2015) em 1991, os índices de envelhecimento superiores a $20 \%$ eram encontrados em poucas microrregiões brasileiras, praticamente todas no estado do Rio Grande do Sul. No entanto, duas décadas depois ou em 2010, este índice subiu para 25\% e passaram a ser encontrados também no sudeste e nordeste brasileiro. Para os autores o que explica este comportamento Rio Grande do Sul são duas razões: o êxodo rural da população jovem e adulta, que foi mais acentuado nessas regiões e a redução mais intensa das taxas de fecundidade. Segundo o último Censo Demográfico de 2010, o percentual de idosos com 60 anos ou mais vivendo no meio rural gaúcho representa $17 \%$ do total da população rural.

A partir do recorte do envelhecimento populacional rural do COREDE, conforme Tabela a seguir, verifica-se um aumento do contingente de idosos a partir do Censo Demográfico de $1991 \mathrm{em}$ todos os municípios. Os municípios com maiores acréscimos ou com maior percentual de idosos no total da população rural, conforme o Censo de 2010 são: Lagoa dos Três Cantos, Colorado, Saldanha Marinho e Selbach com percentual acima de $12 \%$. Por outro lado, em $50 \%$ dos municípios a população idosa rural não chega a $10 \%$.

O trabalho de Mera e Neto (2014a, b) relativo ao COREDE Alto Jacuí salienta que a diminuição ${ }^{9}$ da população rural deste conjunto de município veio acompanhada do aumento da população com 60 anos ou mais chegando a 64,7\% considerando o meio rural e urbano. Ainda, conforme os autores, os idosos no meio rural cresceram em torno de 33\% representando $10 \%$ da população rural do COREDE em 2000 e 11,5\% em 2011. Conforme concluem os autores, uma geração que nasceu no final da $2^{a}$ guerra mundial está reconfigurando o meio rural da região, são $11,5 \%$ de pessoas residindo em propriedades rurais com mais de 60 anos.

Entre os impactos deste processo de envelhecimento, especialmente sociais, estão atrelados às dificuldades dos pais em manter as atividades produtivas nas propriedades. Com o aumento da idade, as pessoas tende a reduzir a força física e a ocupação do seu tempo nas atividades agropecuárias. $\mathrm{O}$ trabalho de Milani et al. (2012) com produtores de leite no norte do RS mostra que o avanço na idade e a ausência dos filhos no papel de sucessores (e mão de obra) leva os produtores a reduzir os investimentos na produção ocasionando a paralisação da atividade no curto prazo. Com a redução da atividade, os produtores passam a ter a aposentadoria rural como a principal fonte de renda.

Outro aspecto diretamente relacionado ao envelhecimento é discutido no trabalho de Spanevello et al. (2017) a partir da perspectiva do destino dos pais e das propriedades quando não há sucessão geracional. Segundo este trabalho, os pais passam a enfrentar os desafios sobre o que fazer com a propriedade fazendo uso de distintas estratégias: a venda para outros proprietários rurais, podendo ser (ou não) os vizinhos; o arrendamento para terceiros, como forma de garantir ainda a posse da propriedade, embora sem produzir ou extrair a renda agropecuária; ou a passagem para os filhos, embora saibam que estes não retornarão para produzir ou viver no campo.

${ }^{9}$ Os autores avaliam este decréscimo através de dados de 1960 até 2010.

Nucleus,v.16,n.1,abr.2019 
Tabela 2: Dinâmica Populacional Rural Idosa no COREDE Alto Jacuí entre o período de 1991 e 2010.

\begin{tabular}{|c|c|c|c|c|}
\hline \multirow[t]{2}{*}{ Municípios } & & \multicolumn{3}{|c|}{ Censos Demográficos } \\
\hline & & 1991 & 2000 & 2010 \\
\hline \multirow{3}{*}{ Boa Vista do Cadeado } & População Rural & 3.028 & 2.202 & 1.969 \\
\hline & População Rural Idosa & 245 & 231 & 230 \\
\hline & $\%$ de Idosos Rurais & 7,42 & 9,35 & 9,42 \\
\hline \multirow[t]{3}{*}{ Boa Vista do Incra } & População Rural & 2.695 & 1.841 & 1.701 \\
\hline & População Rural Idosa & 128 & 137 & 221 \\
\hline & $\%$ de Idosos Rurais & 4,23 & 6,0 & 9,11 \\
\hline \multirow[t]{3}{*}{ Colorado } & População Rural & 3.084 & 2.153 & 1.706 \\
\hline & População Rural Idosa & 360 & 415 & 514 \\
\hline & $\%$ de Idosos Rurais & 8,19 & 10,19 & 14,48 \\
\hline \multirow{3}{*}{ Cruz Alta } & População Rural & 2.281 & 2.693 & 2.227 \\
\hline & População Rural Idosa & 4.063 & 5.103 & 6.208 \\
\hline & $\%$ de Idosos Rurais & 6,33 & 7,58 & 9,88 \\
\hline \multirow[t]{3}{*}{ Fortaleza dos Valos } & População Rural & 2.196 & 2.166 & 1.582 \\
\hline & População Rural Idosa & 201 & 316 & 451 \\
\hline & $\%$ de Idosos Rurais & 4,77 & 6,34 & 9,86 \\
\hline \multirow[t]{3}{*}{ Ibirubá } & População Rural & 6.038 & 5.047 & 3.968 \\
\hline & População Rural Idosa & 1.278 & 1.587 & 2.144 \\
\hline & $\%$ de Idosos Rurais & 7,20 & 8,55 & 11,10 \\
\hline \multirow{3}{*}{ Lagoa dos Três Cantos } & População Rural & 1.713 & 952 & 791 \\
\hline & População Rural Idosa & 196 & 148 & 246 \\
\hline & $\%$ de Idosos Rurais & 9,36 & 9,10 & 15,39 \\
\hline \multirow[t]{3}{*}{ Não Me Toque } & População Rural & 3.316 & 2.619 & 1.970 \\
\hline & População Rural Idosa & 856 & 1.117 & 1.568 \\
\hline & $\%$ de Idosos Rurais & 6,48 & 7,75 & 9,84 \\
\hline \multirow[t]{3}{*}{ Quinze de Novembro } & População Rural & 2.441 & 1.939 & 16,92 \\
\hline & População Rural Idosa & 310 & 367 & 477 \\
\hline & $\%$ de Idosos Rurais & 9,04 & 10,25 & 13,06 \\
\hline \multirow{3}{*}{ Saldanha Marinho } & População Rural & 1.679 & 1.303 & 942 \\
\hline & População Rural Idosa & 228 & 234 & 371 \\
\hline & $\%$ de Idosos Rurais & 6,85 & 7,32 & 12,93 \\
\hline \multirow[t]{3}{*}{ Salto do Jacuí } & População Rural & 1.831 & 2.095 & 1.672 \\
\hline & População Rural Idosa & 388 & 596 & 911 \\
\hline & $\%$ de Idosos Rurais & 4,27 & 5,17 & 7,67 \\
\hline \multirow[t]{3}{*}{ Santa Bárbara } & População Rural & 3.875 & 2.541 & 1.844 \\
\hline & População Rural Idosa & 429 & 592 & 849 \\
\hline & $\%$ de Idosos Rurais & 4,28 & 5,88 & 9,62 \\
\hline \multirow{3}{*}{ Selbach } & População Rural & 2.525 & 2.073 & 1.479 \\
\hline & População Rural Idosa & 314 & 439 & 600 \\
\hline & $\%$ de Idosos Rurais & 6,86 & 9,03 & 12,17 \\
\hline \multirow[t]{3}{*}{ Tapera } & População Rural & 2.224 & 1.948 & 1.628 \\
\hline & População Rural Idosa & 532 & 795 & 1.120 \\
\hline & $\%$ de Idosos Rurais & 5,59 & 7.53 & 10,72 \\
\hline
\end{tabular}

Fonte: IBGE (Censo Populacional, 1991-2010). Elaborado pelos autores.

$\mathrm{O}$ avanço na idade também requer um repensar dos pais sobre o amparo na velhice. Spanevello et al. (2017) pondera que gerações passadas, os filhos que assumiam a função de sucessores recebiam também a tarefa de cuidar dos pais. Este cuidado é definido como o amparo econômico e médico devido ao avanço da idade e da impossibilidade de executar as tarefas produtivas da propriedade. Como encaminhamento, muitos pais migram para os centros urbanos mais próximos. 


\subsection{Acréscimo na expectativa de vida e queda nos níveis de fecundidade no COREDE Alto Jacuí}

A taxa de fecundidade, segundo o IBGE, é representada pelo número médio de filhos que uma mulher teria ao final de sua idade reprodutiva. Conforme esta mesma fonte em 1940, as mulheres brasileiras tinham em média 6,2 filhos, em 1970 caiu para 5,8 filhos e em 2000 chegou a 2,3 filhos (IBGE, 2007).

Considerando as regiões brasileiras, em 2000, a região Norte apresenta taxas mais altas do que a média nacional $(2,3)$, enquanto a região sudeste apresenta a taxa menor seguida da região sul com média de menos de 2,0 filhos por mulheres (IBGE, 2007). O estado do Rio Grande segue a tendência nacional e, segundo dados de Zuanazzi (2015), em 2010 apresentava o percentual de 1,75 filhos por mulheres enquanto em 2000 este valor era de 2,16. Para Zuanazzi (2015) esta tendência brasileira e gaúcha caracteriza-se num estado avançado de transição demográfica semelhante à Europa. Wong e Carvalho (2006) salientam que a maior parte dos países europeus levou quase um século para completar essa mesma transição. Suécia e Inglaterra, por exemplo, levaram cerca de seis décadas para diminuir $50 \%$ de seus níveis de fecundidade, enquanto que o Brasil experimentou um declínio similar em apenas um quarto de século. Esta situação reflete na queda da fecundidade que vem se mostrando generalizada em todo o território brasileiro, embora as desigualdades socioeconômicas tenham adiado em partes o início desse processo nas regiões menos desenvolvidas.

As taxas de fecundidade da região que abrange o COREDE Alto Jacuí são de 1,78 (ZUANAZZI, 2015). De acordo com a Tabela 3, apenas quatro municípios têm percentual maior de filhos por mulheres: Não Me Toque, Saldanha Marinho, Salto do Jacuí e Santa Barbara. Apesar desta constatação, olhando internamente os municípios em questão, verifica-se que todos apresentam um decréscimo da taxa de fecundidade acompanhando a tendência estadual e nacional.

Tabela 3: Esperança de vida ao nascer e fecundidade no COREDE Alto Jacuí entre o período de 1991 e 2010.

(Continua)

\begin{tabular}{|c|c|c|c|c|}
\hline \multirow[t]{2}{*}{ Municípios } & & \multicolumn{3}{|c|}{ Censos Demográficos } \\
\hline & & 1991 & 2000 & 2010 \\
\hline \multirow[t]{2}{*}{ Boa Vista do Cadeado } & Esperança de vida ao nascer & 69 & 74,9 & 76 \\
\hline & Taxa de fecundidade total & 2,2 & 2,6 & 1,4 \\
\hline \multirow[t]{2}{*}{ Boa Vista do Incra } & Esperança de vida ao nascer & 70,6 & 75,2 & 77,0 \\
\hline & Taxa de fecundidade total & 2,2 & 2,1 & 2,0 \\
\hline \multirow[t]{2}{*}{ Colorado } & Esperança de vida ao nascer & 68,6 & 74,1 & 75,1 \\
\hline & Taxa de fecundidade total & 2,1 & 2,0 & 1,7 \\
\hline \multirow[t]{2}{*}{ Cruz Alta } & Esperança de vida ao nascer & 68,6 & 73,6 & 76,5 \\
\hline & Taxa de fecundidade total & 2,9 & 2,2 & 2,2 \\
\hline \multirow[t]{2}{*}{ Fortaleza dos Valos } & Esperança de vida ao nascer & 69,0 & 73,2 & 75,2 \\
\hline & Taxa de fecundidade total & 2,2 & 2,1 & 1,7 \\
\hline \multirow[t]{2}{*}{ Ibirubá } & Esperança de vida ao nascer & 69,0 & 72,9 & 75,9 \\
\hline & Taxa de fecundidade total & 2,5 & 2,1 & 1,6 \\
\hline \multirow[t]{2}{*}{ Lagoa dos Três Cantos } & Esperança de vida ao nascer & 70,6 & 75,4 & 76,1 \\
\hline & Taxa de fecundidade total & 2,1 & 2,0 & 1,2 \\
\hline \multirow[t]{2}{*}{ Não Me Toque } & Esperança de vida ao nascer & 68,6 & 74,0 & 75,8 \\
\hline & Taxa de fecundidade total & 2,2 & 2,0 & 1,9 \\
\hline \multirow[t]{2}{*}{ Quinze de Novembro } & Esperança de vida ao nascer & 69,0 & 73,6 & 75,5 \\
\hline & Taxa de fecundidade total & 2,7 & 2,4 & 1,8 \\
\hline \multirow[t]{2}{*}{ Saldanha Marinho } & Esperança de vida ao nascer & 69,1 & 74,9 & 75,5 \\
\hline & Taxa de fecundidade total & 2,2 & 2,1 & 2,4 \\
\hline \multirow[t]{2}{*}{ Salto do Jacuí } & Esperança de vida ao nascer & 66,4 & 71,5 & 75,2 \\
\hline & Taxa de fecundidade total & 3,1 & 2,4 & 2,0 \\
\hline
\end{tabular}


Tabela 3: Esperança de vida ao nascer e fecundidade no COREDE Alto Jacuí entre o período de 1991 e 2010.

(Conclusão)

\begin{tabular}{lllll}
\hline \multicolumn{1}{c}{ Municípios } & & \multicolumn{3}{c}{ Censos Demográficos } \\
\cline { 3 - 5 } & & $\mathbf{1 9 9 1}$ & $\mathbf{2 0 0 0}$ & $\mathbf{2 0 1 0}$ \\
\hline Santa Bárbara & Esperança de vida ao nascer & 69,0 & 72,6 & 75,5 \\
& Taxa de fecundidade total & 2,4 & 2,3 & 2,2 \\
\hline Selbach & Esperança de vida ao nascer & 68,6 & 74,9 & 75,5 \\
& Taxa de fecundidade total & 2,1 & 2,0 & 1,5 \\
\hline \multirow{2}{*}{ Tapera } & Esperança de vida ao nascer & 67,2 & 71,9 & 75,1 \\
& Taxa de fecundidade total & 2,3 & 2,0 & 1,8 \\
\hline
\end{tabular}

Fonte: IBGE (Censo Populacional, 1991-2010). Elaborada pelos autores.

A esperança de vida ao nascer é o indicador utilizado para compor a dimensão Longevidade do Índice de Desenvolvimento Humano (IDH). De acordo com o IBGE (2017) a esperança de vida ao nascer (ou o número de anos que uma pessoa pode viver), subiu 1940 a 2015 de 45,5 anos para 75,5 anos, ou seja, um aumento de 30 anos. Em 2015, segundo o IBGE (2017), o estado de Santa Catarina apresentava a maior expectativa de vida ao nascer (78,7 anos), sendo o Rio Grande do Sul o quarto estado (com expectativa de 77,5 anos). Dentre os municípios apresentados na Tabela 3, todos apresentam aumento da expectativa de vida nos três Censos analisados. No entanto, nenhum município supera a média ${ }^{10}$ do estado. Analisando esta variável para os municípios que compõe o COREDE Alto Jacuí constatou-se que o município de Boa Vista do Incra possui o maior índice referente a esperança de vida ao nascer, ou seja, no referido município a estimativa é que as pessoas vivam em média 77 anos, ou seja, mais próximo da média estadual. Em contrapartida, os municípios de Colorado e Tapera possuem os menores índices representados por 75,1 anos.

\section{CONSIDERAÇÕES FINAIS}

De modo geral, o comportamento demográfico da população rural se apresenta ao longo das últimas décadas marcadas pela migração juvenil, envelhecimento das gerações mais antigas que permanecem no campo associado ao aumento da expectativa de vida e decréscimo da taxa de fecundidade. Este comportamento da população da região analisada assemelha-se a um processo maior que acontece a nível estadual e nacional que segue a tendência do ocorrido com países europeus em décadas anteriores.

No entanto, é preciso ponderar o que estes processos representam para as regiões rurais como é o caso da região do COREDE analisado. Em tese, estes processos refletem menor disponibilidade de mão de obra no campo, especialmente juvenil, o que pode significar também a perda do potencial inovador, uma vez que são as novas gerações que maior habilidade com as inovações tecnológicas e gestão dos negócios agropecuários devido ao maior grau de escolaridade e maior acesso aos meios de comunicação comparativamente as gerações mais antigas. Da mesma forma, este decréscimo juvenil associado a menor número de filhos por mulher rural compromete a renovação da população rural, inclusive a formação de novas famílias.

Por sua vez, o aumento da expectativa de vida tem permitido as pessoas no meio rural viver mais, o que pode significar ficar mais tempo no campo exercendo a produção agropecuária e gerando renda das propriedades. No entanto, o avanço na idade também pode significar limitações ao trabalho rural, gerando a necessidade dos pais em migrar para as cidades devido aos cuidados com a saúde, ocasionando a

${ }^{10}$ É preciso ponderar que a média do estado é de 2015 e os municípios apresentam a média de 2010, ou seja, mais antiga.

Nucleus,v.16,n.1,abr.2019 
redução das estruturas das comunidades rurais, tais como espaços religiosos e de lazer devido a redução da população no campo. Estes processos demográficos representam impactos sociais importantes nos espaços rurais e sugerem pensar alternativas para que estas regiões mantenham a dinâmica produtiva e socioeconômica ou o seu desenvolvimento rural como um todo.

Contudo, é preciso ressaltar as limitações deste trabalho destacando-se o fato da sua abrangência ser apenas regional, ou seja, com apenas um COREDE. Esse fato implica na necessidade da realização de pesquisas nos demais 27 COREDES como forma de realizar uma análise no contexto do Rio Grande do Sul para verificar o comportamento populacional rural e até mesmo comparar se as dinâmicas demográficas são semelhantes ou distintas.

\section{REFERÊNCIAS}

ALVES, J. E. D.; CAVENAGHI, S. Tendências demográficas, dos domicílios e das famílias no Brasil. Aparte Inclusão Social em Debate. Rio de Janeiro, 2012. Disponível em:

http://www.ie.ufrj.br/aparte/pdfs/tendencias demograficas e de familia 24ago12.pdf. Acesso em: 20 dez. de 2016.

ANJOS, F.S.; CALDAS, N.V. O futuro ameaçado: o mundo rural face aos desafios da masculinização, do envelhecimento e da desagrarização. Ensaios FEE, Porto Alegre, v.26, n.1, p.661- 694, jun. 2005. Disponível em: https://revistas.fee.tche.br/index.php/ensaios/article/view/2097/2479. Acesso em: 25 out. de 2016.

ÁVILA, R.I.; MACHADO, A.M. Transição demográfica brasileira: desafios e oportunidades na educação, no mercado de trabalho e na produtividade. Porto Alegre: FEE, 2015. (Texto para discussão, 133).

PIERRE, B. Reprodução Proibida: a dimensão simbólica da dominação econômica. In: PIERRE, B. O campo econômico: a dimensão simbólica da dominação. Tradução Roberto Leal Ferreira. Campinas: Papirus, 2000. p. 93-119.

BANCO MUNDIAL. Envelhecendo em um país mais velho. Relatório, 2011. 64p. Disponível em: http://siteresources.worldbank.org/BRAZILINPOREXTN/Resources/38171661302102548192/Envelhecendo Brasil Sumario Executivo.pdf. Acesso em: 12 out. de 2017.

BRUMER, A. As perspectivas dos jovens agricultores familiares no início do século XXI. In: RENK, A.; DORIGON, C (Orgs). Juventude rural, cultura e mudança social. Chapecó: Argos, 2014, p. 115-138.

CAMARANO, A. A.; ABRAMOVAY, R. Êxodo rural, envelhecimento e masculinização no Brasil: panorama dos últimos 50 anos. Rio de Janeiro: IPEA, 1999. Disponível em:

http://www.ipea.gov.br/portal/index.php?option=com_content\&view=article\&id=3929. Acesso em: 25 out. de 2017.

CARVALHO, J. A. M.; GARCIA, R. A. O envelhecimento da população brasileira: um enfoque demográfico. Cadernos de Saúde Pública, Rio de Janeiro, v. 19, n. 3, p. 725-733, maio/jun. 2003.

CHAMPAGNE, P. La reproduction de l'identité. Actes de la Recherche en Sciences Sociales, Paris, n. 65, p. 41-64, nov. 1986.

CORRÊA, et., al. Planejamento Estratégico de Desenvolvimento Regional: Conselho Regional de Desenvolvimento Alto Jacuí. COREDE Alto Jacuí - Cruz Alta: UNICRUZ, 2010. 128p. 
DE MERA, C. M. P.; NETTO, C. G. M. Diminuição da População Rural na Região do Alto Jacuí/RS: Análise sob a Perspectiva dos Segmentos Rurais. Desenvolvimento em Questão, v. 12, n. 27, p. 216-263, 2014 a. Disponível em: http://dx.doi.org/10.21527/2237-6453.2014.27.216-263. Acesso em: 10 out. de 2017.

DE MERA, C. M. P.; NETTO, C. G. M. Envelhecimento dos produtores no meio rural na região do Alto Jacuí/RS e consequente migração. Estudos Interdisciplinares sobre o Envelhecimento, Porto Alegre, v. 19, n. 3, p. 759-774, 2014 b.

FROEHLICH, J. M. et al. Êxodo seletivo, masculinização e envelhecimento da população rural na região central do RS. Ciência Rural, Santa Maria, v. 41, n. 9, p. 1674-1680, set. 2011. Disponível em: http://www.scielo.br/scielo.php?script=sci_arttext\&pid=S0103-84782011000900030. Acesso em: 10 set. de 2017.

FUNDAÇÃO E ECONOMIA E ESTATÍSCA. Evolução populacional dos COREDES e suas migrações. 2016. Disponível em:

https://www.fee.rs.gov.br/wp-content/uploads/2016/11/20161116alto-jacui.pdf. Acesso em: 24 de out. 2017.

GASSON, R.; ERRINGTON, A. The farm family business. Wallingford: Cab International, 1993.

GODOI, D. S. A transição demográfica e os impactos sobre o mercado de trabalho brasileiro.

Trabalho de Conclusão de Curso em Ciências Econômicas. UFRGS, 2014, 70 p.

INSTITUTO BRASILEIRO DE GEOGRAFIA E ESTATÍSTICA. Em 2015, esperança de vida ao nascer era de 75,5 anos. Disponível em:

https://agenciadenoticias.ibge.gov.br/2013-agencia-de-noticias/releases/9490-em-2015-esperanca-devida-ao-nascer-era-de-75-5-anos.html. Acesso em: 13 nov. de 2017.

INSTITUTO BRASILEIRO DE GEOGRAFIA E ESTATÍSTICA. Censo Demográfico - 1991. Tabela 200 - População residente, por sexo, situação e grupos de idade. Disponível em: http://www.sidra.ibge.gov.br/bda/tabela/listabl.asp? $\mathrm{z}=\mathrm{cd} \& \mathrm{o}=2 \& \mathrm{i}=\mathrm{P} \& \mathrm{c}=200$.

Acesso em: 20 nov. de 2016.

INSTITUTO BRASILEIRO DE GEOGRAFIA E ESTATÍSTICA. Censo Demográfico - 2000. Tabela 200 - População residente, por sexo, situação e grupos de idade. Disponível em: http://www.sidra.ibge.gov.br/bda/tabela/listabl.asp? $\mathrm{z}=\mathrm{cd} \& \mathrm{o}=2 \& \mathrm{i}=\mathrm{P} \& \mathrm{c}=200$. . Acesso em: 1 nov. de 2016.

INSTITUTO BRASILEIRO DE GEOGRAFIA E ESTATÍSTICA. Censo Demográfico - 2010. Tabela 200 - População residente, por sexo, situação e grupos de idade. Disponível em:

http://www.sidra.ibge.gov.br/bda/tabela/listabl.asp? $\mathrm{z}=\mathrm{cd} \& \mathrm{o}=2 \& \mathrm{i}=\mathrm{P} \& \mathrm{c}=200$.

Acesso em: 20 nov. de 2016.

INSTITUTO BRASILEIRO DE GEOGRAFIA E ESTATÍSTICA. Tendências demográficas no período de 1950/2000 - uma análise da população com base nos dados dos censos demográficos de 1940 e 2000. Rio de Janeiro, 2007.

LISBOA, M. C.; BAGOLIN, I. P. Evolução da distribuição geográfica da população gaúcha, 1970-2000. In: Encontro de Economia Gaúcha, 4, 2009, Porto Alegre. Anais...Disponível em: https://www.fee.rs.gov.br/4-encontro-economia-gaucha/.../localizacao-sessao4-3.doc. Acesso em: 14 nov. de 2017.

MAIA, A. G. O esvaziamento demográfico rural. In: BUAINAIN, A. M.; ALVES, E.; SILVEIRA, J. M. da; NAVARRO, Z.. (Orgs.). O mundo rural no Brasil do século 21: a formação de um novo padrão agrário e agrícola - Brasília, DF: Embrapa, p. 1082-1100, 2014. 
MAIA, A. G.; BUAINAIN, A. M. O novo mapa da população rural brasileira. Revista Franco -

Brésiliene de Géographie, $n^{\circ}$ 25. 2015. Disponivel em: https://confins.revues.org/10548?lang=pt. Acesso em: 22 nov. de 2017.

MILANI, R. et al. A diversificação e perspectivas de investimentos entre produtores de leite. In: Encontro de Economia Gaúcha, 6, 2012, Porto Alegre. Anais... Disponível em:

http://cdn.fee.tche.br/eeg/6/mesa15/Diversificacao e Perspectivas de Investimentos entre Produtores d e Leite.pdf. Acesso em: 23 set. de 2017.

MILANI, R. et al. A agricultura familiar no Brasil: entre a política e as transformações da vida econômica. In: GASQUES, J. G.; VIEIRA FILHO, J. E. R., NAVARRO, Z. (Org.). A agricultura brasileira: desempenho recente, desafios e perspectivas. Brasília, DF: IPEA/MAPA, 2010. p. 185-209. Disponível em: https://www.embrapa.br/busca-de-publicacoes/-/publicacao/904333/a-agricultura-familiarno-brasil-entre-a-politica-e-as-transformacoes-da-vida-economica. Acesso em: 2 nov. de 2016.

NEVES, J. A. S.; SCHNEIDER, S. Brazilian demographic transition and the strategic role of youth. Espace Populations Sociétés, Lille, v. 2, n. 3, p. 2-20, 2015. Disponível em: https://eps.revues.org/5774. Acesso em: 10 mai. de 2017.

SILVESTRO, M et al. Os impasses sociais da sucessão hereditária na agricultura familiar. Brasília: EPAGRI/NEAD, 2001.

SPANEVELLO, R. et al. A Problemática do Envelhecimento no Meio Rural sob a Ótica dos Agricultores Familiares sem Sucessores. Desenvolvimento em Questão, v. 15, p. 348-372, 2017. Disponível em: http://dx.doi.org/10.21527/2237-6453.2017.40.348-372. Acesso em: 01 nov. de 2017.

SPANEVELLO, R. et al. As estratégias para manter a sucessão em estabelecimentos familiares. In: RENK, A.; DORIGON, C (Orgs). Juventude rural, cultura e mudança social. Chapecó: Argos, 2014, p. 163-188.

VAN DER PLOEG, J. D. Camponeses e Impérios Alimentares: Lutas por Autonomia e Sustentabilidade na Era da Globalizacao. Editora da UFRGS: Porto Alegre, 2008.

WONG. L. L. R.; CARVALHO, J. A. O rápido processo de envelhecimento populacional do Brasil: sérios desafios para as políticas públicas. Revista Brasileira de Estudos Populacionais, São Paulo, v. 23, n. 1, p. 5-26, jan./jun. 2006. Disponível em:

http://www.scielo.br/scielo.php?script=sci_arttext\&pid=S0102-

30982006000100002\&lng=en\&nrm=iso\&tlng=pt. Acesso em: 4 set. de 2017.

ZUANAZZI. P. T. A taxa de fecundidade no RS por regiões funcionais e características socioeconômicas: o desafio da transição demográfica. Indicadores Econômicos, Porto Alegre, v. 42, n. 4, p. 109-122, 2015. 